\title{
LA SITUACIÓN POLÍTICA DE CASTILLA A FINES DEL SIGLO XIII
}

\author{
Miguel-Ángel LADERO QUESADA
}

La conquista del reino de Murcia por Jaime II en 1296 y la incorporación de una parte del mismo a la Corona de Aragón, integrándolo en el de Valencia, en 1304, es el objeto o motivo principal de este Congreso y, a siete siglos de distancia, podemos considerarla en sí misma, analizando los detalles de la intervención militar y el juego de relaciones políticas entre los reinos de Aragón, Castilla, Portugal, Granada y Francia que la hicieron posible, o bien podemos situar aquellos acontecimientos en contextos temporales y argumentales mayores, de tipo geohistórico, estructural y coyuntural pero sin perder de vista que los sucesos no fueron consecuencia necesaria 0 resultado ineluctable de esas tendencias y realidades históricas más amplias sino una posibilidad —la que realmente ocurrió — entre otras que también podrían haber ocurrido. Procuraré combinar ambos procedimientos, estudiando la cuestión desde el punto de vista castellano para permitir su contraste con los que han adoptado otros ponentes.

\section{ESTRATEGIAS DE EXPANSIÓN Y COLONIZACIÓN}

La primera intención de control político del Levante andalusí por parte de los reyes de Castilla y León se había manifestado con el establecimiento de protectorado militar y percepción de parias sobre el taifa de Zaragoza, desde los últimos años de Fernando I y en el reinado de Alfonso VI, y con las actividades de este monarca en el S.E. (dominio del enclave de Aledo) y, en especial, del Cid, que bloquea los intentos de cobro de parias y control militar de los condes de Barcelona y domina Valencia durante unos años. El intento se producía dentro de un proyecto político muy ambicioso, que buscaba la sumisión indirecta de los poderes andalusíes a Alfonso VI como Imperator totius Hispaniae. El proyecto terminó definitivamente con la incorporación de aquellas tierras al dominio almorávide, proceso coetáneo a la crisis política que 
padece el reino castellano-leonés tras la muerte de Alfonso VI (1109) y al éxito de Alfonso I de Aragón como conquistador del valle medio del Ebro (toma de Zaragoza, 1118).

Cuando Alfonso VII quiso reconstruir el edificio político del Imperio hispánico, las circunstancias y el reparto de poder habían variado mucho tanto en la España cristiana como en al-Andalus, de modo que una estrategia de control del eje del Sistema Ibérico y de expansión hacia el Levante andalusí tenía que partir de otros supuestos ${ }^{1}$. Al morir Alfonso I de Aragón (1134), intentó por un momento tomar el control de Zaragoza, pero se avino a reconocer el dominio del Regnum Caesaraugustanum por Ramón Berenguer IV como princeps de Aragón por sus esponsales con Petronila, y continuó además otra vía de intervención en al-Andalus, en especial en Levante mediante la protección a Abu Sha'far Ahmad ben Hud, Sayf al-Dawla (Zafadola), hijo del último rey musulmán de Zaragoza. Tras la muerte de éste, en 1146, tomaría su lugar en Murcia y Valencia, Muhammad ben 'Abd Allah ben Sa'ad ben Mardanish, frecuente aliado de Alfonso VII y de sus sucesores contra los almohades hasta su muerte en 1172.

Mientras tanto, se producían los primeros tratados entre Aragón y Castilla destinados a delimitar las futuras zonas de conquista en torno al eje de la cordillera lbérica. En el de Tudellén, 1151, se trató por una parte del reparto de Navarra y, por otra, Alfonso VII reconoció a Ramón Berenguer IV los reinos de Valencia, Denia y Murcia como zonas de su conquista dentro del vasallaje que le prestaba como Imperator totius Hispaniae. En el de Cazola, 1179, donde también debió tratarse de Navarra, Alfonso VIII de Castilla suprimió el vasallaje debido por Alfonso II de Aragón, y le reconoció el reino de Valencia como zona de expansión, pero el de Murcia - al S. de la línea BiarJátiva- sería para Castilla.

En el contenido de estos tratados influían los proyectos a largo plazo pero, sobre todo, las circunstancias próximas y el conocimiento de las propias fuerzas y de los objetivos en los que preferentemente debían emplearse, de modo que interpretarlos con puntos de vista más recientes puede ser inadecuado. Parece bastante claro que, más allá de la cuenca del Ebro y del macizo de Teruel, desaparecía entonces la capacidad real de expansión y colonización territorial catalana y aragonesa - como lo muestra la larga vida del señorío independiente de Albarracín-, y que Alfonso II estaba interesado con mucha mayor frecuencia en empresas occitánicas y mediterráneas. Alfonso VIII, por el contrario, contaba con recursos militares y de colonización mucho mayores y mantuvo siempre como principal objetivo la expansión territorial en la península.

1 Son muy interesantes las consideraciones que hace J.M. LACARRA DE MIGUEL, "Acerca de las fronteras en el valle del Ebro (siglos VIII-XII)", En la España Medieval, 1 (1980), 181-191. Algunas reflexiones de conjunto en mis trabajos, "Cordillères et fleuves dans la formation de l'Espagne médiévale", en J. Fr. Bergier, ed., Montagnes, Fleuves, Forêts dans l'Histoire. Barrières ou lignes de convergence?, Scripta Mercaturae Verlag, St. Katharinen, 1989, pp. 71-83, y, "Las regiones históricas y su articulación política en la Corona de Castilla durante la Baja Edad Media», En la España Medieval, 15 (1992), 213-147. 
Estas premisas, más la reunificación castellano-leonesa desde 1230 , contribuyen a explicar la forma en que se produjeron las grandes conquistas a costa de al-Andalus, entre 1225 y 1265 . El tratado de Almizra (1244) refleja la realidad de las fuerzas y las capacidades en presencia: Fernando III, y en su nombre el infante heredero Alfonso, sujetaba a protectorado al taifa de Murcia y consolidaba el ámbito de expansión fijado en Cazola, al S. del puerto de Biar y de Játiva, no sin algunos roces previos al acuerdo; unos años antes, en 1232, al ofrecer protección al taifa de Niebla, el rey había efectuado una maniobra semejante, destinada a pre-fijar la frontera con Portugal en el Guadiana, pero con este reino no había tratados de reparto tan nítidos que debieran ser objeto de revalidación o cambio.

Jaime I respetó los límites fijados en Almizra cuando entró en Murcia, año 1266, para sofocar la revuelta de los mudéjares, en apoyo de su yerno Alfonso X. Además de cumplir lo pactado, actuaba inteligentemente pues la situación en Valencia era también muy tensa; añadir un nuevo ámbito de responsabilidad habría aumentado la carga a soportar mientras que mantenerlo en manos de un aliado frente al peligro común la disminuía. ¿Tiene este mismo sentido su cooperación a la repoblación de Murcia con colonos catalanes y aragoneses $\mathrm{o}$, por el contrario, era parte de un proyecto de incorporación que entonces se vio frustrado pero que no dejaría de tener repercusiones en los acontecimientos futuros? ¿Corresponden a la realidad o son argumentos creados a posteriori las protestas de nobles catalanes y aragoneses ante la actitud de Jaime I, y la actitud del heredero Pedro, que participó en la campaña y manifestó su deseo de modificar lo tratado en Almizra e incluso de reservar una parte del reino de Granada - la de Almería - a la conquista catalano-aragonesa?

Es muy posible que la breve pero importante obra repobladora de Jaime I en Murcia se inscriba en un proyecto más amplio de control de las costas del SE. peninsular, con o sin dominio político directo. Importa establecer su alcance y dimensiones lo mejor posible, deslindar lo que es propaganda de lo que puede ser realidad, y no inferir de la procedencia de los colonizadores una inmediata consecuencia política; aunque hubieran querido permanecer bajo dominio de Jaime I, lo que no sucedió, ¿hay que suponer que todos ellos o, más bien, sus descendientes, mantenían aquel criterio treinta años después por motivos "nacionales"?, ¿no es preferible pensar que se plantearían la cuestión de acuerdo con criterios prácticos y próximos, de acuerdo con las posibilidades vivas en 1296? La fijación posterior de la frontera, de los poderes y de las poblaciones durante siglos puede llevar a interpretar erróneamente realidades y actitudes anteriores menos sensibles hacia quién fuera el rey titular del poder, siempre que contara con títulos legítimos, actitudes que serían propias tanto de gobernados como de gobernantes: recordemos los proyectos de disgregación de reinos en los testamentos de Jaime $I$, e incluso en el de Alfonso $X$ en el suyo de 1284.

Los estudios de Torres Fontes sobre la repoblación de Murcia muestran, por otra parte, que la de Jaime I fue sólo una de las fases colonizadoras, la segunda entre seis, y no la más importante, destinada a dotar con abundantes tierras a pocos «hombres de valor", en torno a un centenar. En realidad, la llegada de colonos procedentes tanto de Castilla como de la Corona de Aragón fue intensa hasta 1277 y continuó con 
dificultades hasta la última década del siglo, antes de 1296, permitiendo el asentamiento de unos 5.000 vecinos «heredados» con sus familias en todo el reino, procedentes la mitad aproximadamente de la Corona de Aragón y otros tanto de Castilla, instalados principalmente en Murcia, Lorca, Orihuela, Alicante, Elche, Cartagena y Mula, mientras que la cifra de población mudéjar disminuia mucho desde 1277 en adelante ${ }^{2}$. Cuando la sentencia arbitral de Torrellas disponga, en 1304, la partición del reino de Murcia, parece que sus vecinos cristianos, independientemente de su origen, permanecerian en una u otra parte: habría cambios, sin duda, sobre todo en los grupos dominantes, pero no tenemos noticias de emigraciones masivas para ubicar a la población de nuevo según el origen catalano-aragonés o castellano suyo o de sus inmediatos antepasados.

\section{FIN DE LA RECONQUISTA Y CAMBIOS POLÍTICOS ESTRUCTURALES}

Hacia 1264 concluye el tiempo de grandes conquistas, coincidiendo con la frustrada revuelta mudéjar en Andalucía y Murcia y con la nueva definición de las relaciones entre Castilla y el emirato vasallo de Granada. Pasados otros diez o quince años, entre 1275 y 1280, se puede dar por terminado el proceso colonizador, en sus grandes aspectos, al tiempo que Castilla había de hacer frente a la nueva situación de guerra producida por los desembarcos merinies en el S., entre 1275 y 1286. Así, en el plazo de veinte años, el escenario tradicional de la política castellana durante dos siglos -conquistas y «repoblaciones»- había desaparecido. En relación con este hecho, pero no sólo por causa suya, ocurrieron por entonces cambios fundamentales en las grandes líneas de la organización y de la acción política del reino.

\section{En los orígenes de la crisis}

Hay pocas dudas sobre el hecho de que la capacidad de expansión territorial acompañada de procesos repobladores había alcanzado un límite, hacia 1275, tanto en Castilla como en Aragón o Portugal. Se ha supuesto a menudo que el esfuerzo grande y rápido de colonización alteró y deterioró el equilibrio de las relaciones económicas y sociales, y de la misma población y su reparto, en Castilla, siendo origen de diversas alteraciones políticas favorables, en definitiva, a la oligarquización en el ejercicio del poder y al estalido de crisis empobrecedoras. Que haya habido una crisis estructural entre 1265 y 1330 aproximadamente, parece cierto y general, pero tal vez no lo es buscar la causa única o principal en un hecho tan específico porque fenómenos tales como las alteraciones monetarias, el alza de precios, el reajuste socio-político que afecta a todo el país, o las mismas crisis económicas más profundas afectaron igualmente a otros países que no tenían los problemas de frontera y colonización propios de Castilla.

2 Un resumen de sus trabajos, J. TORRES FONTES, «Los repartimientos murcianos del siglo XIII", en De al-Andalus a la sociedad feudal: los repartimientos bajomedievales, Barcelona, 1990, pp. 71-94. También sus estudios y ediciones, La reconquista de Murcia en 1266 por Jaime I de Aragón, Murcia, 1967, Repartimiento de Lorca, Murcia, 1977, Repartimiento de Orihuela, Murcia, 1988. 
El dominio de las nuevas tierras, e incluso el peligro de la frontera en el S., tenía también aspectos favorables: permitía la colonización y disminuía, con ello, riesgos de superpoblación. Permitía también la plena organización del espacio castellano-leonés, la atribución de tierras, la extensión del sistema urbano y de relaciones mercantiles, el desarrollo de la trashumancia ganadera, la apertura de una fachada marítima de primera categoría económica, como era la Andalucía atlántica, la práctica del oficio militar y la ocupación de rentas, parias y botín por parte de la aristocracia, en relación con él. ¿Por qué hubo de ser todo esto, considerado en sí mismo, sólo una fuente de distorsiones, crisis y retroceso de la riqueza del reino?

Los origenes de la crisis hay que buscarlos más bien en la tensión creada por el proyecto político de incremento del poder en manos de la monarquía, que en Castilla se desarrolla desde el reinado de Alfonso $X$, y en otros aspectos de cambio en los anteriores equilibrios de reparto de poder y renta. También, en la reiteración de problemas sucesorios y minoridades regias entre 1275 y 1325 , que facilitaban los enfrentamientos violentos y la abundancia de abusos y depredaciones con su secuela de ruina, empobrecimiento y despoblación. A esto se añadían las apetencias de los reinos comarcanos, tendentes a disminuir la fuerza política de Castilla. También, la endémica guerra del sur - la llamada «batalla del Estrecho»-, que resultó muy gravosa social y económicamente, sobre todo en Andalucía y, además, frenó y distorsionó el proceso repoblador del sur y sus resultados sobre la propiedad y uso de la tierra.

Los orígenes de la crisis están también, desde luego, en las modificaciones de la estructura económica debidas a la primera gran expansión de la actividad mercantil, tanto interna como exterior, y de los instrumentos monetarios, con desmedidos efectos inflacionistas. Y en la pugna de los grupos sociales con fuerza política por adaptarse a los nuevos modos de percepción de renta y librarse de los malos efectos que provocaba el deterioro o ruina de alguno de los antiguos. $Y$ en los cambios paulatinos en el régimen de explotación de la tierra, que beneficiaban a unos grupos más que a otros. $Y$, posiblemente, en la incidencia especial de calamidades naturales, más frecuentes desde comienzos del siglo XIV -pensemos en la carestía y hambre de 13011302-, que coadyuvaron al comienzo de una larga fase de recesión poblacional.

La valoración combinada de estos factores, y aun de otros, puede ser diversa pero tiene que evitar apriorismos interpretativos. Parece claro que su presencia combinada, en forma de haces cambiantes según lugares y momentos, explica mejor los orígenes y el desarrollo de la crisis que no la apelación a un solo factor dominante, ya sea local o general ${ }^{3}$.

3 Estos aspectos están tratados y anotados con mayor extensión en mi trabajo, «La Corona de Castilla: transformaciones y crisis políticas (1250-1350)", en Europa en los umbrales de la crisis (12501350), Pamplona, 1995, pp. 275-322 (XXI Semana de Estudios Medievales, Estella, 1994). 


\section{El crecimiento del poder real}

Me centraré ahora en cuestiones relativas a los cambios en el ejercicio del poder real y en sus relaciones con la sociedad política porque su conocimiento permitirá explicar mejor el trasfondo de los sucesos ocurridos entre 1295 y 1304.

El ejercicio del poder real entre Alfonso $X$ y Alfonso XI ha abarcado ámbitos relativamente nuevos y se ha practicado en circunstancias distintas a las de tiempos anteriores. Hubo un desarrollo de los fundamentos y los instrumentos del poder, ocurrido dentro del marco de transformaciones amplias en las relaciones entre sociedad y poder real: en la segunda mitad del siglo XIII culminó el desarrollo de lo que se ha venido denominando «Estados estamentales», formados sobre una teoría política que integra diversos estamentos socio-jurídicos y diversas realidades territoriales en un cuerpo común, el reino, cuya cabeza es el monarca. De esta concepción del reino como universitas se deducen unos corolarios de unidad e indivisibilidad del conjunto, de vasallaje natural de todos sus habitantes con respecto al rey, y de justificación del orden social establecido sobre la base de desigualdades y jerarquías regladas para cada estamento, con lo que se legitima a la vez al rey como cabeza sin la que no puede existir el cuerpo político, y a diversos sectores como "sociedad política» cuya participación en el poder es indispensable: la alta nobleza, las jerarquías eclesiásticas, los grupos dominantes en los ámbitos locales. Es, en suma, una concepción política que supera, integrándolas, las diversidades y peculiaridades propias del orden feudal - cuyas manifestaciones son tan diversas en unos y otros reinos- y que sustenta un conjunto de ideas sobre el poder y su ejercicio que no admite criterios de cambio constitucional impuestos por las crisis políticas o las luchas sociales. Pero como éstas existen, los cambios también, sobre todo cuando protagonizaban la demanda grupos sociales con fuerza suficiente para modificar la realidad del poder aunque respetando siempre los fundamentos de su estructura estamental y de su configuración en torno a la realeza.

En el desarrollo del estado monárquico bajomedieval hubo dos posibilidades que desembocaron en resultados relativamente distintos. La primera es la posibilidad autoritaria, que concentra poder en la institución regia: en ella, el rey es el único polo constitucional y ejerce el poder sin limitaciones constitucionales apreciables, aunque las tenga fácticas, y muchas con frecuencia. Desarrolla la posibilidad de un estado más fuerte, compacto y dinámico en el que la potencia regia y su control de algunos resortes de cambio en las relaciones de poder son compatibles con una efectiva supremacía social y política de los grupos dominantes. Frente a este modelo que, en definitiva, permanece más abierto desde el punto de vista regio, la posibilidad pactista se basa en la presencia de dos polos constitucionales, el rey y el reino o sociedad política, compartimentada en varios estamentos con gamas de intereses no coincidentes. La realeza está inserta en unas redes sociopolíticas poco flexibles y de escasa movilidad como tales, a no ser que los grupos dominantes tengan el dinamismo adecuado para promoverla porque, por su parte, la realeza-Estado apenas puede emerger más allá de los intereses estamentales. 
En su caminar político entre los siglos XIII y XVI, Castilla y Portugal se organizaron más bien según el primer modelo y Aragón a tenor del segundo, pero al comenzar la segunda mitad del siglo XIII todo estaba por hacer, a partir de tradiciones y situaciones distintas, cosa que siempre conviene recordar. Alfonso $X$ aprovechó las castellano-leonesas para sentar las bases doctrinales y comenzar el desarrollo institucional de un proyecto político en torno al poder real que llevaba al desarrollo de la soberanía y el absolutismo monárquicos. Las reacciones sociales desde 1272 y las crisis políticas desde 1275 matizaron su desenvolvimiento, que estuvo casi bloqueado en muchos aspectos hasta 1325-1330, y se produjeron reajustes tocantes a la consolidación del poder social -y de la participación política - de la alta nobleza y de las aristocracias locales, poder y participación que se renuevan y desarrollan ampliamente a lo largo de toda la baja Edad Media.

Este análisis de las transformaciones del poder real en aquellos primeros tiempos de cambios y crisis ha de referirse a tres aspectos fundamentales: el desarrollo de las doctrinas políticas y de los fundamentos legales e instituciones de gobierno en primer lugar. La creación de un sistema hacendístico nuevo, en segundo, para considerar por último las características y campos de acción de la política económica regia ${ }^{4}$.

\subsection{Teoría política, leyes, instituciones}

La obra legislativa de Alfonso $X$ tiene una importancia decisiva en la organización y en la misma concepción política de la sociedad bajomedieval castellana. El monarca «no promovió ninguna maniobra formalmente derogatoria del Derecho consuetudinario» (J. M. Pérez-Prendes) pero intentó elaborar una obra legislativa escrita basada en el Derecho Común, capaz de arrinconar al derecho consuetudinario y no escrito en unos casos (Espéculo, Partidas) y de limitar los poderes señoriales y acrecentar los de las ciudades realengas en otros (Fuero Real). La obra legislativa alfonsina hizo crisis en la coyuntura de la revuelta nobiliaria de 1272 pero su influencia perduró: los reyes que le sucedieron se limitaron a legislar por ordenamiento y a menudo sobre cuestiones concretas, y es bien sabido como Alfonso XI, en el promulgado en 1348 ante las Cortes de Alcalá de Henares, fijó el orden de prelación de fuentes jurídicas en su uso por los jueces: primero, la legislación real; segundo, los fueros municipales en uso, salvo «lo modificable a criterio real»; tercero, las Partidas; cuarto, el criterio del rey, en cuanto que sólo a él «corresponde el aclarar, enmendar, suplir e interpretar cualquier laguna de la ley».

4 Resumo puntos de vista y contenidos expresados en otros trabajos míos, especialmente: "La genèse de l'État dans les royaumes hispaniques médiévaux (1250-1450)", en Le premier âge de l'État en Espagne. 1450-1700, Paris, 1989, pp. 9-65, «El ejercicio del poder real en la Corona de Aragón: instituciones e instrumentos de gobierno. Siglos XIV y XV», En la España Medieval (Madrid), 17 (1994), pp. 31-93, "Algunas reflexiones generales sobre los orígenes del Estado Moderno en Europa», en La historia política europea como proceso integrador, Buenos Aires, Asociación Argentina de Profesores Universitarios de Historia de Europa, 1995, pp. 27-46, «Poderes públicos en la Europa medieval (Principados, Reinos y Coronas)", XXIII Semana de Estudios Medievales de Estella, julio 1996 (en prensa), y el ya citado "La Corona de Castilla: transformaciones y crisis políticas...". 
En las Partidas se contiene una exposición doctrinal sobre los fundamentos de la vida política, en especial sobre el oficio regio, y también un «diseño de funciones y competencias sobre el que el rey establece un marco institucional preciso y diversificado de la administración militar, financiera, jurisdiccional y del gobierno de la casa, corte y cancillería” (R. Pérez-Bustamante). En ambos aspectos, los textos alfonsinos abren un tiempo nuevo en la historia castellana -y aun hispánica en general pues las Partidas se tradujeron al catalán y al portugués---, más allá de su vigencia o aplicación. Algo semejante cabe decir en lo que se refiere a la fundamentación de la vida política en una conciencia de identidad que se plasma, aprovechando una ya larga tradición, en la obra historiográfica alfonsí (Estoria de España o Primera Crónica General). Muchas transformaciones de las ideas y las prácticas políticas dependen de este fundamento durante toda la Edad Media tardía, e incluso en los tiempos modernos.

Por otra parte, Alfonso $X$ no fue ese «intelectual inadaptado a la vida activa» política que a menudo se ha imaginado sino el promotor de innovaciones institucionales concretas de primera importancia en todos los ámbitos del gobierno y la administración regios. En lo que se refiere a los oficios de la casa real, conserva los dos principales, Mayordomo y Alférez, al tiempo que potencia o crea otros: en el primer aspecto, el oficio de Repostero Mayor — que cederá mucha de su importancia al de Camarero Mayor en tiempos de Sancho IV-. En el segundo, establece los de Almirante Mayor y Justicia o Alguacil Mayor, así como los Alcaldes de Corte (1274), que debían entender en los llamados "casos de Corte»: la promoción de la justicia regia mediante éstas y otras instituciones es una de las claves principales del programa político alfonsí. La cancillería regia se tecnificó con la creación de los Notarios Mayores de León, Castilla y Andalucía, a los que se añadiría otro para el reino de Toledo en 1295 al comenzar la minoría de Fernando IV, cuando se vino abajo la potencia política del arzobispo de Toledo y canciller mayor, Gonzalo Pérez Gudiel. Alfonso X introdujo también una concepción y un reparto nuevos de las delegaciones territoriales del poder real al crear entre 1253 y 1263 la figura de los Adelantados Mayores de la Frontera (Andalucía), Castilla, León, Murcia y Galicia, sustituyendo en los territorios donde los había antes a los Merinos Mayores. Aunque éstos reaparecen entre 1268 y 1272 y el régimen de Adelantamiento sufre un eclipse temporal, se había creado un marco jurídico-administrativo que llegaría a su madurez un siglo después, en época de Enrique II.

Las reformas alfonsinas abrieron un proceso de institucionalización del ejercicio del poder que continuaría durante toda la baja Edad Media porque subsistieron y fueron objeto de perfeccionamiento en los reinados siguientes. En los inmediatos, apenas encontramos novedades, salvo en lo que se refiere a los intentos de constitución de un Consejo del rey estable en las minoridades de Fernando IV y, en especial, de Alfonso XI, y a la paulatina aparición de la Audiencia en la corte regia, que se detecta en 1312 y, de nuevo, a mediados del siglo XIV.

Las reformas y desarrollos institucionales son característicos de todos los reinos occidentales durante la Edad Media tardía pero la precocidad y energía con que las promovió Alfonso $X$ en Castilla tienen mucho de singular y contribuyen a explicar, junto con otras causas, la potencia política indiscutida que el poder y la justicia regias 
tuvieron pese a los momentos de debilidad práctica, a los compromisos de facto 0 al control, también fáctico, por otras fuerzas sociopolíticas.

\subsection{Fiscalidad, moneda, política económica}

Por su parte, la creación de un nuevo sistema de Hacienda regia fue un terreno en el que la capacidad de innovación y diseño de un nuevo orden político propia de Alfonso $X$ se manifestó con especial claridad y en el que sus iniciativas tuvieron continuidad e influencia desde el primer momento y proporcionaron a sus sucesores un instrumento político de primera importancia. La obra alfonsina no comenzó, en estos aspectos, de manera escalonada, a partir de 1252, sino abruptamente, para responder a la crisis producida por la revuelta mudéjar de 1264, por el aumento de precios y por el de las necesidades financieras de la monarquía causado por la alianza con Francia — boda del heredero Fernando en 1269-y por los costos del fecho del Imperio. El rey venía obligado a ello, también, porque de la Hacienda regia dependía una parte notable del nivel de rentas de la alta nobleza e incluso de los caballeros ciudadanos, que percibían tierra -en dinero- como vasallos del rey, y participaban por esta vía, y por otras, del poder político regio, y parece claro que esa parte se incrementó en los años que ahora estudiamos, debido al empobrecimiento o quiebra de otras fuentes de renta de la aristocracia.

La secuencia de innovaciones muestra cómo el rey comenzó a pedir y recibir servicios extraordinarios, otorgados por las Cortes, desde 1269. Cómo aumentó enormemente la cabeza de pecho que pagaban los judíos, desde 1280. Cómo hizo respetar las diversas regalías fiscales - salinas, minas-. Cómo conservó para la Corona todos los almojarifazgos del sur, y en su seno comenzaron a percibirse las primeras alcabalas regias sobre las compraventas. Cómo organizó el régimen aduanero con un tipo general del diez por ciento, en especial desde 1268, y estableció al año siguiente un servicio sobre los ganados trashumantes. Además, desde 1265 se consolidó la percepción de ingresos sobre las rentas eclesiásticas y la recaudación de limosnas para la cruzada, mediando permiso pontificio; al primero de ambos aspectos corresponde el cobro de los dos novenos del diezmo eclesiástico (tercias reales) y de décimas sobre el conjunto de la renta eclesiástica.

Así, Alfonso X introducía novedades importantísimas que permitían concentrar más renta en manos del rey $y$, con ello, más medios de poder. Es cierto que su obra hubo de sufrir el contragolpe de las resistencias puestas por el reino en las Cortes, y el de los abusos y anarquía nobiliaria, en especial durante las minoridades regias, debidos en parte a los desajustes que las nuevas formas de percepción y distribución de renta generaban, pero lo cierto es que las clases privilegiadas hubieron de consentir y colaborar en aquel aumento de la presión fiscal, que apenas les afectaba directamente, porque, en definitiva, beneficiaba a su propio nivel de rentas y a su poder. De hecho, todas las iniciativas de Alfonso $X$ sobrevivieron porque los antiguos derechos y rentas ciertas de la Corona estaban ya consignados en su casi totalidad al pago habitual de tierras a nobles vasallos del rey o del heredero del trono, según se demuestra en los 
libros de cuentas de 1290 y 1292, y gran parte de los nuevos ingresos tenían como destino pagar servicios y colaboraciones de miembros de la sociedad política.

Unos decenios más tarde, desde 1333 y 1342, Alfonso XI generalizó el cobro de alcabala, consolidando las esporádicas imposiciones de sisas que habían efectuado Sancho IV y Fernando IV $(1292,1309 . .$.$) , reformó el cobro del monopolio de la sal y$ recuperó la casi totalidad de los montazgos que pagaba el ganado. Es difícil cuantificar la presión fiscal introducida por aquellas reformas. El análisis de las cuentas de 1290-1292 y las de la Frontera de 1294 sugiere que las rentas y derechos ciertos o tradicionales podían ascender a unas 200.000 doblas de oro, con tendencia a disminuir fuertemente debido a las quiebras monetarias. A pesar de este factor, y de las dificultades e irregularidades en el cobro, las novedades hacendísticas habrían permitido multiplicar por tres esta cifra y situar los ingresos anuales de la monarquía en torno a unas 600.000 doblas anuales hacia 1345.

Las reformas fiscales y sus efectos sobre el orden político y social no pueden comprenderse al margen de otras formas de influencia e intervención política sobre la economía del reino que el mismo Alfonso $X$ también, si no inició, al menos les dio una dimensión y un sesgo nuevos. La intervención más directa se refiere a la moneda, cuya acuñación era regalía efectivamente mantenida. Es posible que los reyes no llegaran a percibir el cúmulo de consecuencias que desencadenaban con sus medidas, salvo en lo relativo al régimen de precios, en el que también procuraron intervenir promulgando tasas $(1252,1258,1268)$, pero la medida principal de Alfonso X fue acuñar en mayor cantidad moneda de vellón e incluso de plata para aumentar la masa monetaria en circulación con piezas más útiles que la de oro para los intercambios interiores y para los tráficos con el exterior. Lo hizo, sin embargo, movido por motivos políticos inmediatos: desde 1258, las pretensiones del rey al título imperial comenzaron a provocar salidas de plata fuera de Castilla. La revuelta contra Granada y la guerra contra Granada de 1264-66 dispararon los gastos militares y llevaron a Alfonso X a acuñar los llamados dineros alfonsíes, moneda de la guerra, blancas o blanquillas, quebrando la ley de la moneda anterior. En 1270-1271 ocurrió otra quiebra al acuñarse los llamados dineros prietos y otra más en 1275 cuando se acuñó moneda nueva blanca: entre 1265 y 1278, la inflación de precios expresados en moneda de vellón fue superior al 500 por 100 . Sancho IV procedió a un nuevo abatimiento o quiebra de moneda al acuñar coronados que recibieron el nombre de novenes, y Fernando IV durante su minoridad disminuyó su ley en una nueva acuñación, acuciado por la escasez de moneda circulante y por el efecto que estaban causando las falsificaciones. Las devaluaciones y la escasez de moneda en uso continuaron al menos hasta 1332.

El medio más simple para medir aquel proceso inflacionario consiste en contemplar cómo evoluciona el valor de la dobla de oro (4.60 g.) expresado en maravedíes, pues el maravedí ya en 1268 era una moneda de cuenta, equivalente a 90 blancas. Pues bien, en 1268 la dobla vale legalmente todavía tres mrs., en 1291 de 20 a 22, en 1310,25 y en 1350,35 .

Las medidas hacendísticas y monetarias de Alfonso $X$ se complementan con otras tendentes a regular la actividad mercantil, que son también una novedad desde los 
años sesenta y crean un vínculo entre política regia y realidad económica antes inexistente o mucho más débil. Las actuaciones alfonsíes recaen sobre una actividad mercantil en auge desde las últimas décadas del siglo XII. Ocurre además cuando el fin de la expansión territorial exige una reorganización del conjunto cuya iniciativa sólo puede corresponder a la monarquía, y más teniendo en cuenta sus intereses hacendísticos y monetarios. En líneas generales, la política regia buscaba liberalizar, dar la mayor fluidez posible al tráfico interior de bienes, al tiempo que se establecían claramente las aduanas con el exterior: ambos aspectos podían lesionar intereses de otros poderes, así como la creación y promoción de numerosas ferias en el realengo y la organización de las cañadas de trashumancia ganadera ${ }^{5}$.

\section{Las relaciones entre poder real y sociedad}

En resumen, es difícil sustraerse a la idea de que el conjunto de hechos ocurrido sobre todo entre 1264 y 1281 ha sido más bien una causa que una consecuencia de los procesos de cambios y crisis: aumento de las necesidades financieras de la monarquía, guerras y revueltas, alteraciones monetarias, innovaciones hacendísticas, nueva política económica. Todo ello alteraba las anteriores relaciones entre poder monárquico y sociedad, y los grupos sociales con gran capacidad de intervención o participación en el poder político tenían que reclamar y proponer, de manera más o menos consciente y definida, reorganizaciones del mismo acordes con los intereses no tanto de un individuo o bando sino también de cada grupo como tal. Veamos cómo se abordó esta cuestión por la alta nobleza, por las aristocracias locales y por los dirigentes eclesiásticos.

\subsection{La nobleza}

La alta nobleza pretendió compartir y mediatizar el poder regio pero, en general, no obstaculizó el proceso de renovación y maduración institucional de los órganos de gobierno monárquicos. Ambos aspectos eran compatibles, de modo que no hubo grandes disputas sobre los cambios en lo que podríamos llamar la arquitectura del poder sino en torno a su uso y control. Sucedía aquello en una situación de cambios en el sistema económico y de inevitable transformación de las fuentes de renta, lo que produjo desajustes y tensiones en la relación entre monarquía y nobleza. Ésta actuó formando bandos poco estables, encabezados por parientes del rey o por miembros de las grandes familias que eran, a la vez, altos cortesanos — Lara, Haro-, sin espíritu de grupo homogéneo ni programa común tal como los llegaría a tener la nobleza que comenzó a aglutinarse en torno a Enrique de Trastámara a mediados del siglo XIV. De hecho, los nobles vieron la posibilidad de satisfacer sus aspiraciones más inmediatas

5 Estudio detallado de muchas de estas cuestiones en mis libros, Fiscalidad y poder real en Castilla (1262-1359), Madrid, Universidad Complutense, 1993, y Las ferias de Castilla. Siglos XII a XV, Madrid, Real Academia de la Historia, 1994. 
apoyándose en las disputas internas de la familia real y en las turbulencias de las minoridades regias: en tales circunstancias, era muchas veces más urgente para unos nobles contrapesar el poder de otros que no formar un frente político común ante la realeza comparable al que había conseguido la nobleza de Aragón en 1282. Por todas estas razones, la actitud nobiliaria entre 1272 y 1325 dio lugar a numerosos desórdenes y alteraciones pero sus resultados en cuanto a vincular por pacto a la monarquía en determinadas coordenadas político-jurídicas fueron nulos y, al cabo, ésta sería la fórmula castellana: los nobles se integran en el poder del rey y lo encaminan hacia su beneficio pero no lo limitan jurídicamente como estamento.

Uno de los grandes argumentos de la historia política durante todo el período fueron las reclamaciones económicas de la nobleza, por la necesidad de suplir con entrega de sueldos y mercedes regias, e incluso con cesiones de jurisdicción a favor de diversos señores en algunas aldeas y villas, la escasez de botín y territorio a repartir, a lo que se añadió la exigencia nobiliaria de que la repoblación de las nuevas tierras y el establecimiento de impuestos regios también nuevos no alteraran ni sus privilegios ni el dominio que ejercían sobre sus solariegos campesinos. Así sucedió que en diversas ocasiones, a partir de 1252, aumentaron los reyes las cantidades asignadas a sus vasallos nobles en concepto de sueldo, así como el número de sus beneficiarios, utilizando para ello las rentas ciertas o foreras, los servicios de las Cortes y otros ingresos, y completándolos con entrega de tenencias de castillos, cesión total o parcial de rentas de diversos lugares, más otros procedimientos diversos, en especial, desde tiempos de Sancho IV, la cesión de aldeas en señorío o heredamiento aunque la «señorialización» estaba todavía muy lejos de alcanzar las enormes dimensiones que tendría en época Trastámara.

A partir de 1295, la capacidad fiscal del reino debió disminuir, empobrecido por guerras, exacciones excesivas, rapiñas y malfetrías de poderosos, quiebras anteriores de moneda, cesiones de lugares en heredamiento, y por la coyuntura creada por malas cosechas. Un cálculo de las rentas regias hecho en 1315 reconocía su mengua, pero no por ello es menos significativo: las rentas ciertas o foreras ascendían a 1.600 .000 maravedies más lo de la Frontera, que sería otro millón, y estaba consignado casi todo a sueldo de ricos hombres y caballeros, pero estos sueldos absorbían mucho más y se estimaba que sería preciso un servicio de Cortes de ocho monedas — de un millón de maravedíes cada una - para pagarlos y atender a los gastos, mucho menores, de mantenimiento del rey y su corte. Veinticinco años atrás, cada moneda de un servicio de Cortes rendía 1.5 millones y bastaban cinco monedas para tales menesteres: cuatro para sueldos y una para el gasto de la casa y corte reales.

\subsection{Las aristocracias locales}

Las aristocracias que dominaban los concejos de realengo no eran un conjunto homogéneo en el que las partes aceptaran un programa de acción política común y único. Sin embargo, la actuación colectiva de los concejos, desde mediados del siglo XIII a mediados del XIV, fue mucho más coherente que la de la alta nobleza con la 
idea de conseguir un pacto con los reyes acerca del ejercicio de su poder puesto que les afectaba de manera directa y gravosa al ser ellos el realengo ${ }^{6}$.

Alfonso $X$ había sido un gran coordinador de la vida política concejil: los concejos no actuarían, según su proyecto, como células de acción contrarias o independientes con respecto al poder regio - nunca lo habían sido-sino que dependerían en buena parte de su voluntad y formarían un sector de la sociedad política estrechamente vinculado a él, de modo que sólo a través de las iniciativas de la monarquía se comprenderia la mayor parte de su actividad, ejecutada por grupos de caballeros y hombres buenos, vasallos del rey que ejercerían los principales oficios concejiles. Este diseño político, como otros del Rey Sabjo, hizo crisis desde 1282 pero sería recuperado, en otras circunstancias, por Alfonso $\mathrm{XI}$ al establecer los regimientos durante su reinado efectivo (1325-1350).

Entre tanto, desde el mismo término de la reconquista, las tensiones entre caballeros y común de los vecinos derivaron en luchas intestinas en casi todas las ciudades y villas, bajo la forma de «alzamientos violentos, más o menos simultáneos, realizados al socaire de las luchas políticas que se desarrollaban en el plano de lo nacional, con un visible trasfondo social y con intervención principalísima de los grupos ciudadanos menos favorecidos» (M. C. Carlé). Los reyes apoyaron, generalmente, al «patriciado" de caballeros y hombres buenos, y se apoyaron en él frente a la alta nobleza cuando esto era inevitable: el ejemplo mejor lo proporciona la reina María de Molina y su actitud en 1295-1301, cuando era tutora de Fernando IV, como desde 1315, cuando lo fue de su nieto Alfonso XI.

El resultado final sería el cuasi-monopolio de los gobiernos concejiles por una oligarquía organizada en bandos en cada ciudad, mucho más presta a integrarse en un juego bipolar nobleza-monarquía de la acción política, como portavoz único de su respectiva ciudad, bastante débil, en definitiva, a la hora de reclamar la existencia de formas de participación colectiva en el ejercicio o al menos en el otorgamiento del poder. Pero, antes de que se alcanzara aquella situación a mediados del siglo XIV, los grupos dominantes de las ciudades actuaron con mayor personalidad en la vida política general, en un sentido afecto al poder monárquico pero, al mismo tiempo, intentando limitar al poder regio por vía de pacto político.

Esto se observa claramente al estudiar la formación de Hermandades y las actuaciones de las Cortes desde 1282, fecha de la formación de la primera hermandad general de ciudades, hasta 1325. La hermandad de 1282, a cambio de apoyar al infante Sancho en el ejercicio de la gobernación del reino, reclamó controlar sus actividades militares, judiciales y legislativas, $y$, sobre todo, que no cobrara sin su consentimiento impuestos desaforados, esto es, al margen de las rentas foreras y que restaurara la moneda en su estado anterior a las quiebras. Sancho IV ignoró estas reivindicaciones sin gran dificultad en cuanto accedió al trono pero a su muerte (1295), de nuevo las ciudades de los diversos reinos que componían la corona formaron her-

6 Un análisis de conjunto sobre estas cuestiones en mi artículo, «Monarquía y ciudades de realengo en Castilla. Siglos XIl a XV», Anuario de Estudios Medievales (Barcelona), 24 (1994), 719-774. 
mandades con idénticos fines, apoyadas en una pretensión de control periódico que garantizarían las reuniones anuales de cada Hermandad y una diputación permanente de las Cortes junto al rey. Por último, desde 1313, durante la minoridad de Alfonso $\mathrm{XI}$, se reprodujo el fenómeno de la Hermandad, más maduro en su manifestación, con pretensiones que guardan mucha semejanza con las que nobles y ciudades habían conseguido en Aragón desde 1282. Pero se trataba de fenómenos coyunturales: desde 1325, Alfonso XI, al dar satisfacción por otras vías a las aspiraciones de dominio del poder local de las aristocracias ciudadanas, acabó con las hermandades como fuerza política, aunque pudieron reaparecer con funciones de orden público en otros momentos de crisis del reino.

Las Cortes reunidas muy frecuentemente durante aquellos decenios, dieron fe del nacimiento de las hermandades y las sirvieron de portavoces pero tampoco consiguieron limitar o compartir de forma institucional los poderes legislativos y hacendísticos de la monarquía que las convocaba y otorgaba o no sus peticiones. Ni siquiera pudieron controlar efectivamente la gestión y gasto del dinero procedente de los servicios que otorgaban. Eran una voz 0 , mejor, un conjunto de voces políticas que el monarca no podía ni quería ignorar, tenían en sus manos algunos resortes de poder -la concesión de servicios-, pero nunca consiguieron limitar legalmente los poderes reales ni obtener un campo propio y permanente de ejercicio y administración del poder más allá de sus funciones de consulta y otorgamiento.

\subsection{Los obispos}

La relación entre la monarquía y el alto clero se caracterizó por el apoyo bastante continuo de los obispos y otros dirigentes eclesiásticos a la política regia, a cambio de la protección y defensa del propio fuero o libertas eclesiástica y de sus fuentes de renta, pero esta afirmación general requiere la explicación de numerosos aspectos de detalle: hubo una colaboración evidente en el crecimiento del poder monárquico pero también resistencias y oposiciones o bien lamentos por el ejercicio malo o abusivo del oficio regio. Pero se aceptaron de mejor o peor grado aspectos fácticos del patrocinio regio y se cedieron a la monarquía fuentes de renta muy sustanciosas (tercias reales, décimas y subsidios, contribuciones extraordinarias, predicación de cruzada) ${ }^{7}$.

La monarquía corresponde a la colaboración habitual de los dirigentes eclesiásticos con la protección a aspectos que éstos consideraban de interés primordial para el ejercicio de su propia autoridad, jurisdicción y ministerio religioso, o para la dignidad de su fuero como estamento privilegiado, incluyendo las exenciones y mercedes fiscales. Pero las intervenciones regias en la vida eclesiástica eran muy fuertes y dieron lugar a veces a quejas colectivas del episcopado, de las que son ejemplo notable los

7 El conocimiento de estas realidades en los trabajos de P. LINEHAN, The Spanish Church and the Papacy in the Thirteenth Century, Cambridge, 1971, History and the historians of medieval Spain, Oxford, 1993, y en los de J.M. NIETO SORIA, en especial, Las relaciones entre monarquía y episcopado en Castilla, 1252-1312, Madrid, 1983, y, Iglesia y poder real en Castilla. El episcopado, 12501350, Madrid, 1988. 
gravamina prelatorum de 1262 y 1279, o las quejas, en 1335, por la opresión fiscal causada por Alfonso XI; no obstante, los reyes tomaron habitualmente medida a favor del estamento eclesiástico, por ejemplo Alfonso X entre 1254 y 1257, Sancho IV en 1282, Fernando IV en 1295 y 1311, Alfonso XI en 1315 y 1326. Los ordenamientos reales dejan traslucir que el defecto de poder regio era para los eclesiásticos peor aún que el exceso, sobre todo en una época que padecía ya el deterioro de las rentas basadas en la producción rural - que eran fundamentales para el clero-, como lo muestran las recaudaciones de décimas de 1309-1311, de modo que la sujeción era preferible a la desprotección, entre otras cosas porque el deterioro del nivel de renta se debía más a las dificultades del momento que no a las cesiones a favor de la monarquía o a las exacciones de ésta. Esta actitud general se mantuvo tanto en tiempo de reyes autoritarios y poco proclives a sujetarse a los puntos de vista eclesiásticos, tal sería el caso de Alfonso X o Alfonso XI, como en el de Sancho IV y Fernando IV, cuya necesidad de apoyo en el episcopado fue mayor, especialmente hasta que se consiguieron, en 1301, las bulas papales de reconocimiento de validez al matrimonio del primero de ambos reyes con María de Molina y de legitimación de sus hijos.

\section{COYUNTURAS, HECHOS Y RESULTADOS DE LA ACCIÓN POLÍTICA}

Para explicar adecuadamente la causas que hicieron posible la conquista de Murcia por Jaime II en 1296 no basta con referirse a las de tipo estructural que hasta ahora hemos examinado puesto que sólo señalan cauces y tendencias básicos que condicionaban la acción política. Hay que conocer también en qué circunstancias concretas se desarrollaba ésta y a qué resultados daba lugar en cada momento, analizando al menos el ámbito temporal inmediatamente anterior y los años mismos de la conquista y de sus consecuencias inmediatas, esto es, entre 1275 y 1305 aproximadamente $^{8}$.

\section{Circunstancias generales}

La intensidad y rapidez de los cambios a que se enfrentan los protagonistas es realmente grande pero, por debajo de ellos, hay unas constantes, unos equilibrios en sus relaciones que nadie está en condiciones de romper más allá de ciertos límites. Es lo que sucede, evidentemente, con las cuestiones de frontera entre los reinos peninsulares, aunque en torno a todas ellas $-y$ aun a la existencia independiente de algunos reinos- había litigios pendientes que alcanzaron solución, casi siempre estable, a lo largo de los treinta años que ahora estudiamos, o en la época inmediatamente posterior - caso de la definitiva reintegración del reino de Mallorca- coinci-

8 Los libros de referencia más completos y de utilidad más inmediata son éstos: M. GONZÁLEZ JiMÉNEZ, Alfonso X (1252-1284), Palencia, 1993. J. O'CALLAGHAN, The Learned King. The Reign of Alfonso $X$ of Castile, Philadelphia, 1993. J.M. NIETO SORIA, Sancho IV. 1284-1295, Paiencia, 1994. C. GONZÁLEZ MÍNGUEZ, Fernando IV (1295-1312), Palencia, 1995. A. MASIÁ DE ROS, Relación castellano-aragonesa desde Jaime II a Pedro el Ceremonioso, Barcelona, 1994, 2 vol. 
diendo con la maduración del concepto de Corona regni indivisible, más allá de la persona y de la voluntad de cada rey.

1. En Navarra, la crisis sucesoria de 1274 volvió a activar las viejas aspiraciones anexionistas por parte tanto de Aragón como de Castilla. Jaime I adujo sus derechos dinásticos y un viejo pacto de prohijamiento que había establecido con Sancho VII, pero no pasó a la acción. Castilla, por el contrario, sí lo intentó: el infante Fernando de la Cerda apoyó con las armas al partido que encabezaba García Almoravit. La decisión de la reina navarra Blanca, al concertar el matrimonio de su hija Juana con uno de los hijos de Felipe III de Francia -el futuro Felipe IV-, reforzó decisivamente la influencia francesa en el reino y bastó para detener las pretensiones castellanas, que quedaron en suspenso en 1277, por voluntad de Alfonso X, y así continuaron a pesar del acuerdo secreto de reparto de Navarra establecido en 1281 por el infante heredero de Castilla, Sancho, y por Pedro III de Aragón. Su presencia en Navarra permitiría a Felipe IV jugar un papel aún más activo en el pleito sucesorio castellano de finales del siglo XIII reavivando problemas de frontera que ya serían tratados en su entrevista de Bayona (abril 1290) con Sancho IV pero que no se resolverían hasta diciembre de 1301, después de fracasar la entrada en Rioja con tropas navarras y aragonesas que había efectuado el noble castellano Juan Núñez de Lara, rebelde a Fernando IV, en mayo de 1299.

2. Para Portugal y Aragón el objetivo estratégico era una modificación limitada de fronteras, que les parecían fijadas en términos demasiado favorables a Castilla. Tal vez considerarían también con agrado una fragmentación interna de la extensa y poderosa corona castellano-leonesa, lo que les permitiría limitar con reinos más reducidos, de potencia similar a la suya, como había ocurrido antes de 1230 , pero esta hipótesis sólo tuvo alguna posibilidad de realización entre 1296 y 1301 y nunca contó con posibilidades efectivas. Dejemos para más adelante el caso aragonés y recordemos muy brevemente que la cuestión fronteriza con Portugal se había planteado de nuevo cuando su rey dejó de prestar vasallaje al castellano por el Algarbe, en 1267 y se resolvió en el tratado de Alcañices (1297), que reconocía a Portugal los términos de Moura, Mourao, Serpa y Olivenza, más los lugares de Riba de Coa (Alfayates, Sabugal, Castel Rodrigo y otros); Dionís I, por su parte, renunció a cualquier otra reclamación territorial, especialmente en Aroche, Aracena y la frontera del Guadiana.

3. El planteamiento de las disputas era totalmente distinto, y mucho más agrio, en la frontera entre Castilla y Granada. El problema fundamental del emirato granadino fue siempre defenderse de Castilla para lo que contó al comienzo con una garantía jurídica, aunque insuficiente, pues había nacido con un pacto de vasallaje de Muhammad I a Fernando III (Jaén, 1246), pero contó, sobre todo, con las dimensiones y características de su territorio, fácilmente defendible, que albergaba además una población densa, en especial después de 1264, superior al comienzo y equivalente, luego, a la de la Andalucía cristiana cuyo apoyo en otras regiones castellanas -en especial las del N. del Tajo- estaba limitado por el hecho mismo de la distancia y por las condiciones en que las guerras se realizaban entonces. Pero, para Castilla, la culminación de las tendencias reconquistadoras y de los esfuerzos para conseguir un 
territorio que pudiera ser organizado sin continuos problemas de frontera, consistía en la conquista de Granada.

Ahora bien, desde 1264 Castilla fue, por diversas circunstancias, incapaz de llevar adelante sus proyectos mientras que los granadinos consiguieron además moverse hasta 1340 en circunstancias generales que favorecían mucho su defensa. El sector más conflictivo de la frontera entre 1275 y 1309 fueron las serranías rondeñas y gaditanas, donde los emires de Granada habían tenido que aceptar, a pesar suyo, la ayuda norteafricana meriní, propiciada además por la actitud insumisa del linaje que gobernaba algunas plazas fuertes del sector, los Asqilula. Para Castilla era un sector clave pues, sin asegurar la paz de frontera, no se podía repoblar gran parte del bajo valle del Guadalquivir, como se demostró durante los desembarcos y ataques de tropas meriníes en $1275,1277,1278$ y 1282 . Evitarlos fue imposible mientras la dinastía meriní tuvo fuerza política y militar en el N. de África pero, al menos, se podian contrapesar aprovechando el enfrentamiento casi continuo entre los sultanes de Granada y Fez, guarneciendo las plazas de frontera como Vejer, Alcalá de los Gazules, Medina Sidonia, Arcos, Morón, Osuna o Estepa, y combinando los ataques terrestres con bloqueos marítimos eventuales que permitieran asediar alguna plaza de desembarco y tomarla: esto es lo que se hizo con Tarifa en 1292 y lo que se intentó en vano hacer con Algeciras en 1278 y 1309 . Tarifa fue durante decenios un punto avanzado estratégico en la batalla del Estrecho, para los musulmanes era fundamental recuperarla y para los castellanos costosísimo sostenerla: se estimó en dos millones de maravedíes anuales el gasto en 1293 aunque Alfonso Pérez de Guzmán se hizo cargo de la alcaidía y defensa de la plaza poco después por sólo la tercera parte de esa cantidad.

En la zona fronteriza de Córdoba, Jaén y Murcia, el enfrentamiento entre granadinos y castellanos se producía casi en solitario, aunque es cierto que los meriníes saquearon la campiña cordobesa en sus primeras campañas $(1275,1277)$, y que los reyes de Aragón tenían interés en el S.E., tanto castellano como granadino. Durante la minoridad de Fernando IV, el emir Muhammad II, aliado de Jaime II de Aragón, tomó Alcaudete, Bedmar y Quesada, plazas adelantadas de la frontera giennense, aunque los castellanos las recuperarían en la ofensiva de 1309 a 1312 al tiempo que, aliados esta vez de Jaime II, que asedió Almería en 1309.

4. La política peninsular de los reyes aragoneses estuvo condicionada por el desarrollo de la que llevaron a cabo en el Mediterráneo, especialmente en la cuestión de Sicilia, desde 1282. Las consecuencias de la intervención de Pedro III tras las vísperas sicilianas en los equilibrios políticos de Aragón y Cataluña fue inmediata: la Unión nobiliaria aragonesa consiguió el llamado Privilegio General (3 octubre 1283), mientras que las Cortes catalanas del mismo año obtenían concesiones muy similares del rey. En ambos casos, se quiebra una línea de crecimiento del poder real, al sujetarlo a pacto, y los reyes habrán de tenerlo en cuenta a la hora de emprender acciones exteriores para no tropezar con resistencias o rebeldías internas y para contar con los apoyos financieros y militares necesarios, siempre más limitados de lo que sería su deseo.

Mientras tanto, la reacción pontificia, francesa y angevina era muy fuerte, pero la 
suerte favoreció a Pedro III, al caer preso Carlos de Salerno, hijo del rey de Nápoles -y de Sicilia-Carlos de Anjou, en 1284. Al año siguiente, fracasaba la expedición francesa a Catảluña destinada a situar en el trono aragonés a Carlos de Valois. Alfonso III, hijo y sucesor de Pedro III en 1285, contó sobre todo con bazas diplomáticas -la prisión de Carlos de Salerno, la retención, como luego veremos, de los castellanos infantes de la Cerda- y procedió a conquistar Mallorca en 1285-1287 acusando a su rey, Jaime, de haber faltado a sus obligaciones como feudatario. Mientras tanto, un hermano de Alfonso III, también llamado Jaime, rey de hecho en Sicilia, contaba con suficientes fuerzas navales para defender la isla. Entre 1286 y 1291, la querella se desarrolló en escenarios diplomáticos, con ganancias efectivas para Aragón en los tratados de Tarascón (1290) y, ya bajo Jaime II, Anagni (1295), en el que se le otorgó la investidura de Córcega y Cerdeña a cambio de devolver el reino infeudado de Mallorca a su rey y a la renuncia a seguir defendiendo Sicilia, donde reinaba su hermano Fadrique, y de contribuir a la guerra contra él. Pero la situación de Fadrique se consolidó en los años siguientes, hasta la paz de Caltabellota (1302). Lo más importante, desde nuestro punto de vista actual, es que Anagni permitió a Jaime II desvincularse de la anterior actitud que había mantenido, de amistad y apoyo a la postura de Sancho IV de Castilla precisamente cuando la muerte de éste le abría - libre ya de problemas mediterráneos- muy buenas perspectivas para aprovechar la débil situación política de la reina viuda castellana y tutora de Fernando IV, María de Molina.

5. La razón última de esta debilidad hay que buscarla en el pleito sucesorio iniciado con la muerte del infante heredero Fernando de la Cerda en 1275, y en el aprovechamiento de la situación por diversas fuerzas políticas, sobre todo la alta nobleza castellana, para conquistar más poder. Cuando el segundogénito de Alfonso $X$, Sancho, fue reconocido heredero en 1276, los hijos de Fernando -Alfonso y Fernando, los llamados «infantes de la Cerda»- pasaron a Aragón y allí fueron acogidos y retenidos por Pedro III, que vio claramente los beneficios políticos posibles en aquella operación. Juan Núñez de Lara, uno de los principales nobles castellanos, se declaró por los infantes y se exilió por algún tiempo en Francia mientras que Lope Díaz de Haro, señor de Vizcaya, apoyaba a Sancho. En 1280, el rey francés Felipe III sugirió a Alfonso $X$ la posibilidad de crear un reino vasallo en Jaén para Alfonso de la Cerda pero, al exponer públicamente el proyecto, el rey castellano desencadenó la rebeldía de Sancho, que se hizo con el poder pero no pudo impedir que su padre le desheredara en su testamento de noviembre 1283-enero 1284: en él se nombraba heredero del trono a Alfonso de la Cerda, y se establecian dos reinos vasallos con Sevilla y Badajoz, del que sería titular el infante Juan, y Murcia, para el infante Jaime, hijos ambos de Alfonso X. El testamento no se cumplió, pero se había abierto una puerta a ambiciones y proyectos territoriales que no concluyeron en 1284 .

La situación se mantuvo estable durante el reinado de Sancho IV (1284-1295) aunque las amenazas y reivindicaciones seguían latentes mientras se añadía otro peligro: el matrimonio del rey con su pariente María de Molina se había realizado sin dispensa pontificia; ésta no se obtenía con la rapidez deseada ni, por lo tanto, era posible legitimar a los hijos. La muerte prematura de Sancho IV convertiría esta situa- 
ción en un problema añadido de gran importancia porque su hijo y heredero Fernando hubo de comenzar su reinado con solo nueve años y sin legitimar. Antes de que ocurriera tal cosa, las circunstancias no eran tan malas: el poder real se había restablecido, la guerra contra los musulmanes concluía en 1286 y era posible pasar a la ofensiva en 1292 (toma de Tarifa); Sancho se libraba en 1288 de la tutela política de Lope Díaz de Haro y vencía años después revueltas de los Lara — que se habían reconciliado también en 1288- y de su hermano el infante Juan, que se exilió en Fez en 1293.

Volvamos por un momento sobre nuestros pasos para observar cómo la idea de que Murcia era un reino desgajable del conjunto castellano, o una baza en posibles negociaciones, se consideró varias veces en aquellos años. El mismo Alfonso III había propuesto en 1286 que se entregara a Alfonso de la Cerda, y Sancho IV y Felipe IV de Francia así lo acordaron en el tratado de Lyon (julio 1288), añadiendo Villa Real (hoy Ciudad Real); en Lyon se estableció que Alfonso de la Cerda casaría con la infanta Isabel y que, si no dejara Sancho IV herederos legítimos -y entonces no los tenía aún- le sucedería en el trono Alfonso. El tratado franco-castellano apuntaba directamente contra Aragón y Alfonso III reaccionó promoviendo los intereses de Alfonso de la Cerda, al que reconoció como rey de Castilla, mientras que éste, en compensación por su apoyo, le cedía el reino de Murcia. Ninguna de aquellas medidas tuvo efectividad pero se llegó a un estado de guerra entre Castilla y Aragón que concluyó con la muerte de Alfonso III y el giro político de su hermano y sucesor Jaime, que desembocó en alianza - tratado de Monteagudo, noviembre de 1291-y en el proyecto de matrimonio entre el rey aragonés y la infanta Isabel, hija del castellano, de ocho años, que se criaría en casa de su futuro marido, con lo que parecía cesar la hostilidad entre ambos reinos y el apoyo que Aragón venía prestando a Alfonso de la Cerda.

El movimiento de posiciones en aquella partida diplomática era, por lo tanto, muy complejo y fluido, pero es de suponer que con Sancho IV vivo y capaz de movilizar la fuerza militar castellana nunca hubiera obtenido Jaime II lo que consiguió en 1296. La conquista del reino de Murcia no fue consecuencia ineluctable ni del cambio de estructuras de poder ni de la dinámica política concreta, que podían haber dado pie igualmente a otros resultados, sino de la ocasión que se presentó al morir Sancho IV y confluir durante la minoridad de Fernando IV todos los factores de debilidad y todas las dificultades políticas que podían afectar a la realeza castellana, a pesar de los esfuerzos que María de Molina llevó a cabo para limitar sus malos efectos, muy especialmente la revuelta de gran parte de la alta nobleza.

\section{Los sucesos de 1295 a 1305}

1. No es objeto de esta conferencia narrar de nuevo los sucesos políticos de los años 1295 a 1305 sino únicamente explicar mejor el porqué de las acciones y proyectos dentro del cuadro general que hemos expuesto hasta ahora. El perfil de los principales actores se puede trazar con relativa seguridad: la reina María de Molina, tutora 
de Fernando IV, defendía con todas sus fuerzas los derechos de su hijo, comenzando por la integridad del reino, continuaba la acción diplomática ante el Papa, fundamental, para que se reconociera la validez de su matrimonio con Sancho IV y se legitimara a los hijos habidos, y contaba con el apoyo de las ciudades y villas de realengo, principales perjudicadas por la prepotencia de la alta nobleza, y también con el de gran parte del alto clero: los prelados presentes en las Cortes de Valladolid, agosto 1295, reconocieron como rey a Fernando IV, Ios arzobispos de Toledo Gonzalo Pérez Gudiel y, sobre todo, Gonzalo Díaz Palomeque, trabajaron sucesivamente en Roma por la obtención de las bulas de legitimación hasta que se consiguieron en 1301, mientras que otros obispos actuaban como mediadores entre las partes en conflicto y apoyaban abiertamente a la tutora, por ejemplo los de Osma, Coria, Palencia, Astorga, Sigüenza o Cartagena.

La actitud de los dos infantes castellanos que actúan durante aquellos años sólo puede calificarse de profundamente perjudicial para los intereses del poder regio tal como estaban definidos desde tiempos de Alfonso X, lo que muestra cómo las tendencias a la fragmentación o a otras formas de reparto del poder político comenzaban en el mismo seno de la familia regia para prolongarse y apoyarse en los planteamientos propios de la alta nobleza. El infante Enrique, hermano de Alfonso $X$, regresa a Castilla, sexagenario, cargado de resentimiento y con el fin de conseguir la máxima promoción y medro personal que se le han negado desde que hubo de exiliarse cuarenta años atrás; su capacidad de maniobra, lo coyuntural de sus alianzas, la ausencia de principios estables en su acción, hacen de él un personaje peligroso e imprevisible. Entre sus proyectos más aberrantes figuró el de vender Tarifa a Muhammad II de Granada para alejarlo de la alianza con Jaime II y acabar con el gasto que causaba su sostenimiento; sólo la determinación de Alfonso Pérez de Guzmán, que llegó a entrar en negociaciones directas con Jaime II, y la falta de apoyo que encontró en Andalucía evitaron que tal cosa sucediera, pero María de Molina hubo de otorgar compensaciones: Pérez de Guzmán fue señor de Sanlúcar de Barrameda desde octubre de 1297 y se consolidó como primer noble con señoríos en la frontera de la baja Andalucía?.

El infante Juan, hermano de Sancho IV, autor de revueltas contra el rey, exiliado en Granada desde 1293, jugó abiertamente la carta de Alfonso de la Cerda y se apoyó en Dionís I de Portugal y Jaime II de Aragón para ser proclamado rey de León en abril de 1296. Sólo en junio de 1300, con la situación en su contra, se avino al reconocimiento de Fernando IV para seguir presente en el escenario político castellano.

Junto a uno u otro infante, y también junto a María de Molina, actúan los miembros de la alta nobleza, con intereses divergentes pero con el objetivo común, que en gran medida consiguieron, de aumentar su poder, sus señoríos y heredamientos y su participación en las fuentes de renta regias. A comienzos de 1296, casi toda la principal nobleza está en contra de Fernando IV: Juan Núñez de Lara lo abandona junto con su

9 Sobre el significado estratégico de Tarifa en aquellos momentos, vid. mi conferencia, "Castilla y la batalla del Estrecho en torno a 1292: la toma de Tarifa", Almoraima. Revista de Estudios Campogibraltareños (Almería), 9 (1993), 15-24. 
pariente Nuño González de Lara para apoyar de nuevo a Alfonso de la Cerda, y también al infante Juan, aunque con reservas, y pelea por sus propios objetivos, entre los que se cuenta el otorgamiento del señorío de Albarracín por Jaime Il. Diego López de Haro hace lo propio, junto con su pariente Juan Alfonso de Haro, pero se mantienen más próximos a María de Molina, y el segundo recibe el señorío de los Cameros a cambio de su fidelidad. Fernán Rodríguez de Castro mantiene el partido del infante en Galicia. Otros nobles como Pedro Díaz de Castañeda, Lope Rodríguez, Ruy Gil de Villalobos o Fernán Ruiz de Saldaña mantienen también una postura inicial de rebeldía que sólo irá modificándose paulatinamente, caso por caso, después del enfrentamiento bélico principal, ocurrido en 1296 , a medida que vayan considerando más conveniente para sus intereses apoyar a Fernando IV.

Las actitudes de Dionís I de Portugal y Jaime II de Aragón son diferentes. Ambos pretendían obtener provecho de la difícil situación castellana pero los objetivos del portugués eran más limitados - la modificación de frontera, el futuro matrimonio entre Fernando IV y su hija Constanza-, los obtuvo ya en las vistas de Ciudad Rodrigo, a mediados de 1295, y sólo el retraso en su cumplimiento le indujo a participar en la guerra, hasta que el tratado de Alcañices (septiembre 1297) resolvió la cuestión y convirtió a Dionís I en un posible mediador, valioso para los intereses de María de Molina.

Jaime Il procuró, en cambio, obtener el máximo beneficio de la situación mediante el desarrollo de una acción política muy inteligente, calculadora y flexible, apoyándose en Alfonso de la Cerda, en la alianza con Muhammad II de Granada y, mientras fue posible, con Portugal, en la buena evolución del conflicto siciliano y de sus relaciones con el pontificado, el rey de Francia y los angevinos desde 1295, y, sobre todo, utilizando en su provecho las rebeldías de infantes y nobles castellanos, y el que éstos vieran en la intervención del rey aragonés una forma de mantener su propia influencia y conseguir sus objetivos en contra del partido realista firmemente encabezado por María de Molina. Sólo a medida que evolucionó este último factor tuvo que ir modificando Jaime II su política porque sus medios para llevarla a cabo - recursos militares y económicos- eran muy limitados. Siempre hubo gran distancia entre las pretensiones y las realidades pero, al cabo, fue él quien obtuvo mejores resultados.

2. La devolución de la infanta Isabel a Castilla con ruptura del compromiso matrimonial, a poco de morir Sancho IV, fue señal de lo que se avecinaba pero los acontecimientos decisivos ocurrieron en 1296. Los acuerdos de Bordalba (Ariza, enero) preveían la entrega del trono de Castilla a Alfonso de la Cerda, del de León al infante Juan, y reconocían la cesión de Murcia a Jaime ll e importantes señoríos en el E. de Castilla para su hermano el infante Pedro: Cuenca, Cañete, Alarcón y Moya. La acción militar ocurrió entre abril y agosto: no tuvo resultados decisivos en Tierra de Campos, que era el corazón de la monarquía castellano-leonesa, aunque el infante Juan se proclamara rey en León, pero Jaime II ocupó el reino de Murcia -salvo Lorca, Mula y, durante varios meses, Alhama- sin encontrar otra resistencia que la de los alcaides de los alcázares de las principales ciudades, sobre todo en Alicante, y las ofrecidas por Orihuela y por Elche; el asedio de Elche se prolongó más de tres meses mientras se llevaban a cabo negociaciones con los representantes de su señor, Juan Ma- 
nuel, nieto de Alfonso X y Adelantado de Murcia, entonces menor de edad ${ }^{10}$. Los factores que ayudan a entender mejor la facilidad con que Jaime II consiguió su objetivo son: la imposibilidad de enviar refuerzos desde otras partes de Castilla, la falta de autoridad para movilizar milicias concejiles en aquella situación de caos político en la que, además, era de prever el escaso o nulo entusiasmo de una parte de los vecinos por la controvertida causa de Fernando IV, y, además, la escasa capacidad defensiva de Murcia, concentrada además frente a Granada, en Lorca sobre todo —recordemos que esta plaza no se rindió a Jaime II hasta finales de 1299-, ante la amenaza de un ataque de Muhammad II en combinación con el de su aliado coyuntural Jaime II. Por el contrario, en el valle del Duero y en las plazas de la zona de Cuenca, no se obtenía nada pues las circunstancias eran muy distintas, ni llegó a haber en ningún momento durante aquellos años enfrentamientos campales ni, salvo excepciones, asedios de plazas concluidos con éxito por ninguna de las dos partes.

Así, el envite guerrero de 1296 no llegó a tener resultados decisivos. Los aragoneses se retiraron del valle del Duero cuando murió el infante Pedro durante una epidemia en el cerco de Mayorga, que duraba ya cuatro meses. Ni el aragonés y sus aliados ni María de Molina tenían capacidad suficiente para asediar y conquistar plazas contrarias, como se demostró en los años siguientes, ni la mayoría de los nobles estaba dispuesta a choques directos, más allá de escaramuzas o tomas pacíficas de castillos previo acuerdo con el alcaide. Pero las ciudades - salvo León-, y casi todas las villas y lugares obedecían a María de Molina, y los nobles rebeldes comenzarían a hacerlo desde finales de 1296, a medida que recibían compensaciones o veían menos posible el triunfo de Alfonso de la Cerda.

3. Sucede, sin embargo, que los conflictos en aquel tiempo tenían un ritmo de desarrollo lento, por la limitación de los medios disponibles y por el papel que jugaban larguísimas y complicadas negociaciones cuyo curso podía verse alterado en cualquier momento por cambios de alianzas, muertes o sustituciones de protagonistas e incluso, aunque más raramente, por éxitos o fracasos decisivos en el terreno militar. Todavía en el transcurso de 1297, Alfonso de la Cerda pudo instalar una pequeña corte en Almazán, tomada para él por Juan Núñez de Lara y dominar la plaza próxima de Deza, en ambos casos por concesión de los dirigentes locales, pero Jaime II estuvo mucho más interesado en los asuntos del ámbito siciliano entre 1297 y 1300 y no quiso implicarse en nuevas operaciones bélicas, ni siquiera para intentar hacer efectiva la cesión que Alfonso le hacía de Molina, Cuenca, Cañete, Alarcón, Moya y Requena. Al parecer, había conseguido ya sus objetivos territoriales de mayor importancia y prefería la negociación.

Vistas así las cosas, la relativa inhibición de Jaime II, el tratado de Alcañices con

10 J.M. DEL ESTAL, «Problema sucesorio de Castilla y anexión de Alicante a la Corona de Aragón», VII Centenario del Infante don Fernando de la Cerda, Ciudad Real, 1976, pp. 237-263. Conquista y anexión de las tierras de Alicante, Elche, Orihuela y Guardamar al Reino de Valencia por Jaime II de Aragón (1296-1308), Alicante, 1982. «Incidencia del problema sículo-sardo en la conquista del reino de Murcia por Jaime II de Aragón (1296-1304)", XI Congreso de Historia de la Corona de Aragón, Palermo, 1984, pp. 25-70. El Reino de Murcia bajo Aragón (1296-1305). Corpus documental, Alicante, 1985-1990, 2 vol. 
Dionís I, la paulatina y bien remunerada vuelta de nobles a la fidelidad debida a Fernando IV, erosionaron mucho en 1297 la posición de Alfonso de la Cerda y sus aliados aunque continuaran las espadas en alto y hubiera maniobras hostiles destinadas sobre todo al empobrecimiento del adversario: rapiñas, saqueos, falsificaciones monetarias. Quien más padecía era el reino pero, por eso mismo, se consolidaba la posición de María de Molina, que defendía, en nombre de su hijo, la vuelta al orden y el fin de los abusos y malfetrías. Los jalones principales en el lento proceso de restauración fueron éstos: primero, la multiplicación de mercedes a nobles y el aumento de adhesiones desde el otoño de 1297. Segundo, la prisión del último gran rebelde, Juan Núñez de Lara, en mayo de 1299, y su retorno a la fidelidad debida a Fernando IV, con gran provecho de Juan Alfonso y Diego López de Haro, y del infante Enrique. Tercero, la reconciliación y acatamiento al rey por parte del infante Juan, en junio de 1300. Cuarto, el fin de la negociación en Roma y la obtención de las ansiadas bulas de legitimación en septiembre de 1301, coincidiendo con la llegada de Fernando IV a una mayoría de edad que se había retrasado hasta los 16 años. Paralelamente, Felipe IV de Francia aseguraba su intención de no hostilizar al rey castellano.

4. El gran perjudicado por la evolución de los acontecimientos era Alfonso de la Cerda, pero tampoco Jaime II debía esperar nuevas ganancias. Por fin, había conseguido tomar Lorca a finales de 1299 y completar así la principal de ellas, que era el reino de Murcia, pieza clave en futuras negociaciones. Pero no podía ir más allá: a pesar de la marginación temporal a que se vio sometida María de Molina al tomar el gobierno Fernando IV, y del inmediato enfrentamiento por el poder en la corte de dos bandos, encabezado uno por el provecto infante Enrique y los Haro y otro por el infante Juan y los Lara, Jaime II tenía un campo de acción negociadora cada vez más limitado, y pesaba sobre él la actitud levantisca de los nobles aragoneses, que se manifestó en 1301. Poco a poco se aproximaba el fin del conflicto y no surgieron elementos nuevos que alteraran aquella tendencia. Todavía en junio de 1303 (vistas de Ariza), el rey de Aragón, el infante Enrique y los Haro declararon su voluntad de que Alfonso de la Cerda fuera reconocido rey de Jaén y señor de Almazán y otras plazas. El infante Enrique murió en agosto y su partido quedó temporalmente debilitado y disperso. Por otra parte, también en junio se había acordado una tregua entre Castilla y Granada. A fines de año sólo se mantenía rebelde Díego López de Haro y Alfonso de la Cerda, en su refugio de Almazán, únicamente podía esperar las compensaciones limitadas que obtuviera para él Jaime II en un proceso negociador que se anunciaba ya inmediato.

Su resultado fue la sentencia arbitral de Torrellas (agosto de 1304), complementada por el tratado de Elche (mayo de 1305). Con ella terminó la primera de las grandes crisis políticas internas que Castilla padeció a lo largo de casi un siglo, entre 1295 y 1393, la que mayor costo tuvo desde el punto de vista de las pérdidas territoriales, y la primera también en desencadenar un proceso de aumento del poder nobiliario -incluyendo en él los numerosos señoríos que recibió Alfonso de la Cerda, y el comienzo de la prolongada y tortuosa carrera señorial del mal llamado infante Juan Manuel-y otro proceso de empobrecimiento del país, pero en 1304 casi todo podía aún enderezarse según los proyectos políticos que Alfonso $X$ había trazado y comenzado a desarrollar. 
5. En definitiva, se puede suscribir la afirmación de A. Masiá de Ros: en todo este asunto, la ventaja estuvo siempre de parte de Jaime, ayudándole en sus ambiciones sobre Murcia. Se nos podrá objetar que no logró enteramente su objetivo, pero creemos que no es pequeño el éxito conseguido, pues aparte de conservar territorios donados por quien no los poseía, consiguió que su antiguo protegido y aliado fuese dotado por el monarca a quien pretendía despojar... Un pedazo de Murcia a cambio de la paz, quedando además Jaime como árbitro de los destinos peninsulares, no puede ser considerado como un mal negocio ${ }^{11}$.

Un pedazo de Murcia... Tal vez en esta expresión se halla la clave para entender dónde estuvo el daño mayor, y no me refiero tanto al ámbito de la vida política como al de la organización social y económica, que no podría aprovechar las potencialidades de la cuenca del bajo Segura en su conjunto. Además, las comunicaciones de Murcia con el resto de Castilla se veían más dificultadas y disminuían mucho, por una parte, el traspaís y los recursos próximos de que podían disponer los murcianos para la defensa de la frontera con Granada y, por otra, las posibilidades mercantiles castellanas en su fachada mediterránea, donde el puerto principal era Alicante, bien enlazado con el interior por Villena y Almansa, y no Cartagena.

No todo concluyó en 1305: el amplio señorío de Villena, cuyo titular fue don Juan Manuel, nieto de Alfonso X, hasta su muerte en 1348, se reintegró en el espacio político castellano, especialmente desde 1366, manteniendo una gran autonomía. Jumilla y Abanilla fueron conquistadas en la guerra de 1356-1358 y volvieron a formar parte del reino murciano. Pero sería deseable que se estudiaran no sólo las consecuencias políticas de los sucesos de 1296-1304 a lo largo de los siglos XIV y XV sino también, especialmente, las sociales y económicas ${ }^{12}$. Si hubo o no emigraciones y reacomodos importantes de población a causa de la nueva frontera; de qué manera se canalizó el tráfico procedente del reino de Toledo hacia Valencia y Alicante más que hacia Cartagena; en qué medida la partición de 1304 aumentó la marginalidad y dificultó la colonización en una Murcia cuya identidad se basó, a pesar de la lejanía, en su condición castellana, tan celosamente mantenida como lo demuestra hoy el archivo municipal de su capital, que es el más completo y el mejor conservado de toda Castilla para los últimos siglos de la Edad Media.

11 Relación castellano-aragonesa..., p. 125.

12 Vid. los puntos de vista de J. TORRES FONTES, La delimitación del sudeste peninsular. I. Tudilén, Cazola, Almizra, Murcia, 1950, Torrellas-Elche, 1304-1305, Murcia, 1951. Los avatares políticos del siglo XIV pueden seguirse en una bibliografía abundante y de calidad. M.T. FERRER I MALLOL, "Abanilla y Jumilla en la Corona catalano-aragonesa (s. XIV)», Homenaje al profesor Juan Torres Fontes, Murcia, I, 1987, pp. 477-490, y, Organització y defensa d'un territori fronterer. La Governació d'Oriola en el segle XIV, Barcelona, 1980. A. PRETEL MARÍN, Don Juan Manuel, señor de la llanura, Albacete, 1982, y, «El cambio dinástico y la crisis de mediados del siglo XIV en el Señorío de Villena», Congreso de Historia del Señorío de Villena, 1987, pp. 305-332. J.L. PASTOR ZAPATA, «Un ejemplo de "apanage" hispánico: el señorío de Villena (1250-1445)», Revista del Instituto de Estudios alicantinos, 31 (1980), pp. 15-40. Una síntesis en Historia de la Provincia de Alicante. III. Edad Media, Murcia, 1985 (pp. 171. 286, "Historia Política», por Juan Manuel del Estal). Y en E. GUINOT RODRÍGUEZ, Els límits del regne. El procés de formació territorial del Pais Valencià medieval (1238-1500), Valencia, 1995. 